\title{
Molecular Mechanisms Linking Adiponectin Receptor Signalling and Cancer
}

\author{
Atsushi Nakajima ${ }^{*}, 1$, Hiroki Endo ${ }^{1}$, Kyoko Yoneda ${ }^{1}$, Toshio Fujisawa ${ }^{1}$, Michiko Sugiyama ${ }^{1}$, \\ Kunihiro Hosono ${ }^{1}$, Yuichi Nozaki ${ }^{1}$, Hirokazu Takahashi ${ }^{1}$, Koji Fujita ${ }^{1}$, Masato Yoneda ${ }^{1}$, \\ Masahiko Inamori ${ }^{1}$, Takashi Shimamura ${ }^{1}$, Noritoshi Kobayashi ${ }^{1}$, Hiroyuki Kirikoshi ${ }^{1}$, \\ Kensuke Kubota ${ }^{1}$, Satoru Saito ${ }^{1}$, Koichiro Wada $^{2}$ and Hitoshi Nakagama ${ }^{3}$ \\ ${ }^{I}$ Division of Gastroenterology, Yokohama City University School of Medicine, Yokohama, Japan \\ ${ }^{2}$ Department of Pharmacology, Graduate School of Dentistry, Osaka University, Osaka, Japan \\ ${ }^{3}$ Biochemistry Division, National Cancer Center Research Institute, Tokyo, Japan
}

\begin{abstract}
Adiponectin is an adipose tissue-derived hormone. It is a key hormone that is responsible for insulin sensitization, and its circulating level is inversely associated with abdominal obesity. Recent studies have shown that a reduced plasma adiponectin level is significantly correlated with the risk of various kinds of cancers. Adiponectin may influence the cancer risk by modulating the metabolic environment indirectly. However several cancer cells express adiponectin receptors, suggesting that adiponectin also may modulate the cancer progression directly. Herein, we review the recent evidence concerning the molecular mechanisms linking adiponectin receptor signaling and cancer. Further studies are required to fully elucidate the molecular mechanisms of the adiponectin-mediated signaling pathway in cancer.
\end{abstract}

Keywords: Adiponectin, colorectal cancer, visceral fat, highfat diet, AMPK, mTOR.

\section{INTRODUCTION}

Adiponectin, which is also referred to as AdipoQ or ACRP30, is a 224 amino acid protein that circulates in human plasma as a homopolymer or as full-length adiponectin (fAd) that comprises 18 monomeric units. Proteolytic cleavage of full length adiponectin produces globular adiponectin (gAd), which is thought to have enhanced potency [1].

It is now well known that the adiponectin receptor exists in two isoforms; adiponectin receptor 1 (AdipoR1), which is abundantly expressed in the skeletal muscle and adiponectin receptor 2 (AdipoR2), which is predominantly expressed in the liver $[1,2]$.

AdipoR1 has high affinity for the globular form of adiponectin, whereas AdipoR2 exhibits intermediate affinity for both the globular and the full length adiponectin. Overexpression and gene manipulation experiments in mice have demonstrated the ability of these receptors to ligand dependently activate the 5'-AMP-activated kinase (AMPK), p38 mitogen-activated protein kinase (p38 MAPK) and peroxisome-proliferator-activated receptor- $\alpha$ (PPAR $\alpha)$, as well as stimulate fatty acids oxidation and glucose uptake in murine hepatocytes [2].

\section{PROPOSED MECHANISM UNDERLYING THE SUPPRESSIVE EFFECT OF CIRCULATING ADIPONECTIN ON VARIOUS KINDS OF CANCER}

Insulin resistance and hyperinsulinemia are well-known risk factors for various kinds of cancer [3]. Adiponectin is

*Address correspondence to this author at the Division of Gastroenterology, Yokohama City University School of Medicine, 3-9 Fuku-ura, Kanazawaku, Yokohama 236-0004, Japan; Tel: +81-45-787-2640; Fax: +81-45-7843546; E-mail: nakajima-tky@umin.ac.jp known to be an "insulin-sensitizing hormone". Therefore, it may be possible that adiponectin improves insulin resistance resulting in an indirect suppression of cancer cell progression. In contrast, several reports, including one from our group, have demonstrated that adiponectin directly inhibits the cancer cell proliferation in vitro [4-6]. These results lead to the hypothesis that there may be two kinds of action of adiponectin on cancer progression and invasion, a direct effect and an indirect effect. In the direct effect on cancer, adiponectin modulates several intracellular signaling pathways via the adiponectin receptors. As noted above, there are two types of adiponectin receptors, AdipoR1 and AdipoR2, and adiponectin can stimulate AMPK, PPAR $\alpha$, and MAPK in classical insulin target organs such as liver and skeletal muscle [2], however it has not been fully elucidated whether these receptor-mediated signaling pathways play any roles in cancer progression.

In the indirect action of adiponectin on cancer, adiponectin may influence cancer risk by modulating the metabolic environment, such as improving insulin resistance.

\section{INDIRECT ACTION OF ADIPONECTIN ON CANCER}

Adiponectin may influence cancer risk through its wellrecognized effects on insulin resistance [3]. Circulating adiponectin concentrations are inversely correlated with fasting plasma insulin [7], and adiponectin stimulates the sensitivity of peripheral tissue to insulin, which leads to a decrease in plasma insulin concentration [8]. Insulin increases bioactive insulin-like growth factor (IGF)-1 through various mechanisms. Growth hormone is the primary regulator of hepatic production of IGF-1, and the expression levels of hepatic growth hormone receptor are partly regulated by insulin $[9$, 10]. Recent evidence has indicated that insulin/IGF-1 is 
associated with an increased incidence or mortality rate for a number of cancers [11]. In addition to their role in metabolism, insulin and IGF axes are major determinants of proliferation and apoptosis and thus may influence carcinogenesis [12]. Previous reviews on the link between insulin/IGF-1 and colorectal cancer risk have focused on the aspects of underlying biological models [13-16], animal models [15], and some epidemiologic evidence $[13,16,17]$. In vitro, insulin is an important growth factor for colorectal mucosal cells and acts as a mitogen for colonic carcinoma cells [18, 19]. IGF-1 inhibits apoptosis and is required for cell cycle progression [20]. Both normal colonic epithelium and colon cancer tissues have insulin and IGF-1 receptors [21, 22]; when activated by IGF-1, the receptor-ligand complex inhibits apoptosis and allows progression through the cell cycle [18, $20,22]$. Therefore, both pre-malignant and cancerous stages of epithelium can be affected by IGF-1. It has also been reported that IGF-1 promotes proliferation and inhibits apoptosis, including that of normal prostate and tumor cells in vitro [23]; and elevated IGF-1 levels in most although not all studies, are associated with an increased risk of prostate cancer, particularly advanced cancer [24]. Considerable evidence suggests that the complex processes that can lead to insulin resistance are likely to play a role in pancreatic carcinogenesis [11]. Furthermore, IGF-1 and IGF-1 receptors are highly expressed in pancreatic cancer cell lines [25], and initiation of intracellular signaling through the IGF-1 receptor leads to an increase in proliferation, invasion, and expression of mediators of angiogenesis and decrease in apoptosis in pancreatic tumor cell lines [26]. The epidemiological evidence of a relationship between plasma levels of IGF-1 and risk of breast cancer has been inconsistent [27-30].

The insulin signaling pathway downstream of the insulin receptor, such as the PI3K/Akt signaling pathway, might be involved in the promotion of cell proliferation. Akt plays an important role in a variety of biological processes including cell survival, cell growth, and oncogenesis [31-33]. Therefore, the PI3K/Akt pathway is believed to play a crucial role in the development of obesity-related cancer (Fig. 1). However, in vivo mechanistic evidence has confirmed that this hypothesis is insufficient.

Although adiponectin decreases the plasma insulin concentration by improving the insulin resistance which may lead to inhibition of the PI3K/Akt signaling pathway and thereby resulting in reducing the cancer risk, there are several well-known insulin sensitizing and desensitizing hormones other than adiponectin such as TNF $\alpha$, leptin, resistin, and free fatty acids. From a physiological viewpoint, the fact that adiponectin or other obesity-related factors do not exist in vivo alone but rather coexist in serum leads to the reasonable assumption that carcinogenesis may be influenced by the activation of several signaling pathways [34].

Further studies are needed to fully elucidate the indirect effect of adiponectin on cancer, especially with regard to other hormones that modulate insulin sensitivity.

\section{PLASMA CIRCULATING ADIPONECTIN, AND ADIPONECTIN RECEPTORS IN RELATION TO CANCER}

Recently, it was reported that adiponectin plays an important role in the suppression of several malignancies.

Miyoshi et al. conducted the case-control study and demonstrated that low adiponectin levels are significantly associated with an increased risk of breast cancer [35]. Mantzoros et al. also showed adiponectin is inversely associated with breast cancer risk, particularly in postmenoposal women [36]. In a prospective case-control study, Tworoger et al. observed no association between adiponectin and

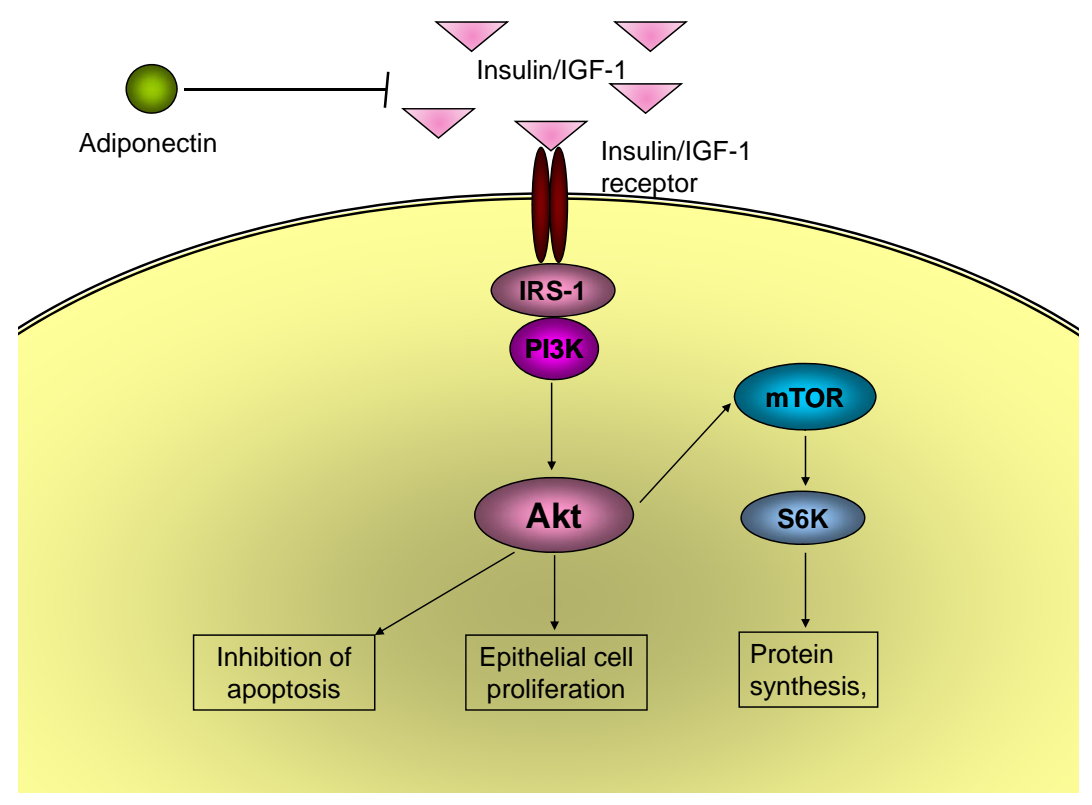

Fig. (1). Schematic illustration of indirect effect of adiponectin on cancer

Under hyperinsulinemia conditions, PI3K/Akt signaling stimulates cell growth and proliferation through many downstream substrates. Adiponectin decreases the plasma insulin concentration by improving the insulin resistance which may lead to inhibition of the PI3K/Akt signaling pathway thereby resulting in reducing the cancer risk. 
breast cancer risk overall, but there was a nearly significant interaction by menopausal status $(p=0.08)$, then they suggested that adiponectin may be inversely associated with postmenoposal breast cancer risk, particularly in a lowesterogen environment [37]. In contrast, Cust et al. did not observe a statistically significant inverse association between adiponectin levels and breast cancer risk in a prospective study in northern Sweden [38].

Petridou et al. showed that plasma adiponectin concentration is inversely and significantly related to the risk of endometrial cancer in a case-control study in Greece [39]. Dal Maso et al. also reported the inverse association with endometrial cancer risk emerged for plasma adiponectin levels in northeastern Italy [40]. Cust et al. conducted the prospective case-control study nested within the European prospective Investigation into cancer and Nutrition to examine the relation between prediagnostic plasma adiponectin levels and endometrial cancer risk, and demonstrated the negative association [41]. In prostate cancer, Goktas et $a l$. showed the negative association between plasma levels of adiponectin and prostate cancer group [42]. Baillargeon et al. showed no association between plasma levels of adiponectin and the prostate cancer risk in a prospective study [43], whereas Sher et al. showed that lower adiponectin was independently associated with high-grade prostate cancer in a prospective study [44].

Kumor et al. reported that the serum concentration of adiponectin in colorectal carcinoma patients was lower than in controls [45], and Wei EK et al. showed that men with low plasma adiponectin levels had a higher risk of colorectal cancer than men with higher levels in a prospective nested case-control study [46]. In contrast, Lukanova et al. reported finding no association between the plasma levels of adiponectin and the risk of colorectal cancer [47], and Stocks T et al. did not demonstrate the negative association between colorectal cancer risk and adiponectin levels in prospective study in Sweden [48]. Therefore the association between the circulating adiponectin and colorectal cancer is controversial. Very recently, our group has demonstrated that the plasma levels of adiponectin are inversely associated with the numbers of Aberrant Crypt Foci (ACF) which is a precancerous lesion of colorectal cancer [49]. These results suggest that the adiponectin plays an important role in inhibiting colorectal carcinogenesis in its early stages.

As for the adiponectin receptors, Korner A et al. first demonstrated that expression of AdipoR1, but not AdipoR2, was higher in breast cancer tissue than both adjacent and control tissues [50]. On the contrary, Takahata et al. showed that AdipoR1 and AdipoR2 were expressed in both normal breast epithelial cells and breast cancer cells, and they also demonstrated that there was no significant difference in the mRNA expression levels of both AdipoR1 and AdipoR2 mRNA between normal breast epithelial cells and breast cancer cells [51]. Michalakis et al. showed that prostate cancer patients had significantly lower plasma adiponectin concentrations as compared with healthy controls. They also showed that AdipoR1 and AdipoR2 may be expressed in both prostate cancer and healthy tissue, however, weaker expressions of AdipoR1 and AdipoR2 were shown in cancerous than in healthy prostate tissue [52]. In an animal study, using azoxymethane induced chemical carcinogenesis mouse model, our group has demonstrated that a lack of adiponectin could promote colon polyp formation only under a high-fat diet condition, not under a normal diet condition, suggesting that adiponectin may play an important role in inhibiting colorectal carcinogenesis only in obese people or in those who eat a Western-style diet. Yoneda et al. demonstrated that AdipoR1 and AdipoR2 were expressed in normal colon epithelium and colorectal cancer tissues and that there was no significant difference in the expression of AdipoRs between normal cells and cancer cells [53]. Williams et al, however, reported that adiponectin receptor was expressed in normal tissue at a significantly lower level than in colorectal cancer [54].

Recently, it was reported that single nucleotide polymorphisms (SNPs) of adiponectin receptor 1 gene was associated with breast cancer risk [55] and colorectal cancer risk [56].

These results suggest the possibility that adiponectin might directly exert action on the suppression of cancer through the adiponectin receptors, which is different from the indirect action mediated by modulating the metabolic environment, such as improving insulin resistance. Further studies are required to elucidate the function of adiponectin and the mechanisms downstream of adiponectin receptors in malignant cells.

\section{DIRECT ACTION OF ADIPONECTIN: ADIPO- NECTIN RECEPTOR SIGNALING AND CANCER}

There are many reports investigating the adiponectin receptor signaling in classical insulin target organs such as liver, muscle and adipose tissues. It is reported that adiponectin stimulates AMPK, PPAR $\alpha$, and p38MAPK via AdipoRs in the classical insulin target organs such as liver and muscle $[1,2]$.

AMPK is a heterotrimetric serine-threonine kinase that senses depletion of intracellular energy and responds by stimulating catabolic pathways that generate ATP [57-61]. Under conditions in which cellular energy demands are increased or when fuel availability is decreased, intracellular ATP concentration is reduced and the AMP level rises. AMP then activates AMPK and triggers a phosphorylation cascade that regulates the activity of various downstream targets, including transcription factors, enzymes, and other regulatory proteins. One of the downstream targets of AMPK is the mTOR (mammalian target of rapamycin) pathway [57]. The phosphorylation of mTOR by AMPK plays an important role in restoring ATP levels by slowing the energy-consumption processes associated with protein synthesis and cell growth. Leptin and adiponectin are two metabolic hormones that regulate the phosphorylation state of AMPK by binding to cell surface receptors and triggering a receptor-mediated transduction cascade. Another route through which AMPK can be regulated is through activation of the tumor supperssor LKB1 [60]. The antidiabetic drugs, thiazolidinedione and metformin, also exogenously activate the AMPK [57].

Several tumor cell lines express AdipoR1 and AdipoR2, which suggests that adiponectin could exert direct effects on these cells via signaling through its receptors. 
However, only a few reports have investigated the adiponectin receptor signaling in epithelial and cancer cells such as those of colon and stomach.

\section{ADIPONECTIN MEDIATES mTOR/S6K SIGNALING PATHWAY IN CANCER}

The mammalian target of rapamycin (mTOR), a member of the phosphoinositide 3-kinase (PI3K)-related kinase family, not only acts as a central controller of protein translation and cell cycle progression but also plays a key regulatory role for growth factors and nutritional status [62-64]. mTOR is a critical component of the PI3K and Akt pathways, and it affects cell proliferation through activation of two protein translational components, ribosomal p70S6 kinase (S6K) and eukaryotic initiation factor (eIF4E) binding proteins (4E-BPs) [65]. S6K phosphorylates the $40 \mathrm{~S}$ ribosomal protein $\mathrm{S} 6$ and stimulates the translation of 5 'terminal oligopyrimidine tracts mRNAs which code for ribosomal proteins and other components of the translational machinery [66]. mTOR-mediated phosphorylation of 4E-BPs dissociates the 4E-4E-BPs complex, freeing $4 \mathrm{E}$ for its primary function of binding to the cap structure of mRNA as part of the translation initiation complex [67]. Tuberous sclerosis complex (TSC) 1 and TSC2 are well known inhibitors of mTOR $[68,69]$, but AMP-activated protein kinase (AMPK) has also been reported to activate TSC1/2 [70] and directly inhibit mTOR activity [71].

In many cancers, aberrant activation of mTOR is observed. Although activating mutations in mTOR itself have not been identified, deregulations of upstream components that regulate $\mathrm{mTOR}$ are prevalent in cancer. Therefore, mTOR has attracted investigators' attention as a target for the molecular therapy of cancer. Clinical trials indicate that rapamycin, a specific inhibitor of $\mathrm{mTOR}$, and rapamycin analogues may be effective in the treatment of multiple types of cancer [72-76].

The relationship between adiponectin and the mTOR pathway is not fully understood and their direct interaction has never been reported. In myocytes and hepatocytes, adiponectin improves insulin sensitivity and increases fatty acid oxidation through phosphorylation and activation of AMPK $[77,78]$. AMPK activation by adiponectin was also observed in adipocytes, pancreatic beta cells and endothelial cells [7982]. Caligiuri et al. and Wang et al. reported that adiponectin inhibits mTOR's downstream effectors through AMPK activation in hepatic stellate cells [83] and in myoblast cells [84], respectively. Regarding cancer cells, we reported that adiponectin decreased cell proliferation in colorectal cancer cells through activation of AMPK and inhibition of mTOR and consecutive molecules [6]. On the other hand, Barb et al. reported that adiponectin activated AMPK but did not inhibit mTOR in prostate cancer cells [85]. Because the effect of adiponectin on the mTOR signaling pathway may be cancer cell type specific, more detailed studies of the role of adiponectin in cancer cells are needed.

Only a few reports have been published on in vivo studies of the effects of adiponectin on the mTOR signaling pathway. Yamauchi et al. reported that treatment with adiponectin increased phosphorylation and activation of AMPK in mice liver [78]. Mariño et al. examined the relationship between adiponectin secretion and activity of the mTOR pathway in skeletal muscle in Zmpste24-/- mice, and found

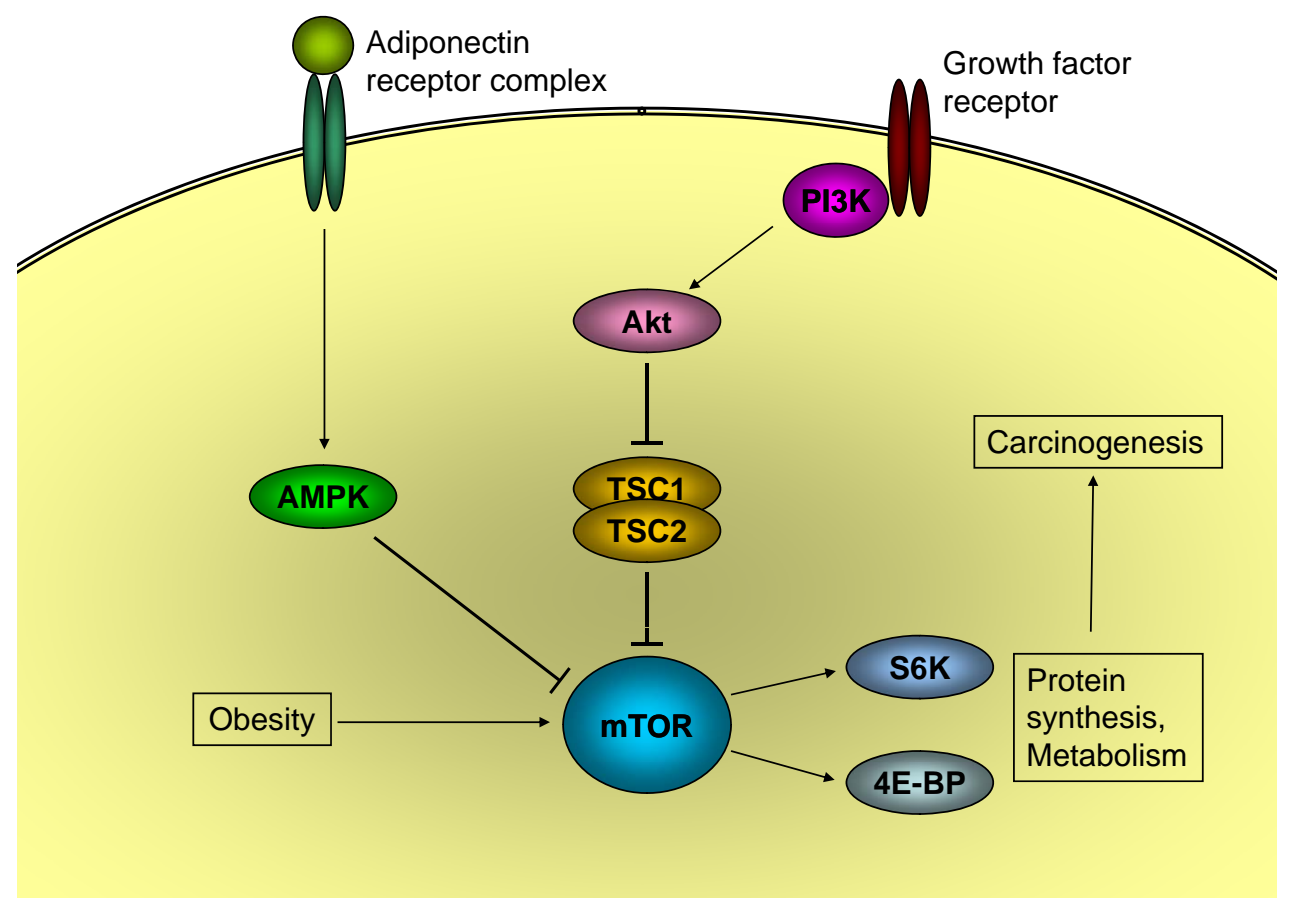

Fig. (2). Signal transduction of adiponectin in mice colon epithelium

mTOR is usually activated by PI3K/Akt pathway. Although high-fat diet induces mTOR activation, adiponectin inhibits the mTOR activation through AMPK. 
that adiponectin secretion conflicted with activities of mTOR and its downstream targets [86]. We investigated the effect of adiponectin on colorectal carcinogenesis using adiponectin-deficient mice, ACRP30-/- mice [87]. Under high-fat diet conditions, adiponectin deficiency promoted proliferation of colorectal epithelial cells and their carcinogenesis but this effect was not seen under normal diet condition. Examining the activation of the mTOR signaling pathway in colorectal epithelium, AMPK phosphorylation was significantly decreased in ACRP30-/- mice and phosphorylation of mTOR, $\mathrm{S} 6 \mathrm{~K}$, and S6 proteins were increased compared to those in wild type mice, but only under high-fat diet conditions. This activation of mTOR signaling pathway was ameliorated by replacement of adiponectin. Furthermore, administration of the specific activator of AMPK, 5-aminoimidazole-4carboxamide-1-b-D-ribofuranoside (AICAR) or the mTOR inhibitor, rapamycin also ameliorated the adiponectin-deficient activation of the mTOR signaling pathway. In a different study, a high-fat diet-induced obesity was associated with an increased activation of the mTOR and its downstream target S6K1 in rat liver and skeletal muscle [88]. These studies suggest that adiponectin controls the activity of mTOR elevated by obesity (Fig. 2). Activated mTOR pathway in adiponectin-deficient was associated with an increased incidence of colorectal polyps. Therefore, the control of activation of mTOR appears to be important for colorectal cancer prevention under high-fat diet conditions.

Adiponectin also increases energy metabolism via PPAR $\alpha$ activation through the expression of genes involved in fatty acid uptake, intracellular transport and oxidation, as well as biosynthetic pathways. A recent report has demonstrated that PPAR $\alpha$ may play an important role in various kinds of cancer. However no other reports have confirmed that adiponectin modulates cancer cells by activating this transcription factor.

Recently, Fenton JI et al. reported that adiponectin inhibited leptin-induced cell proliferation of intestinal preneoplastic cells, and that this inhibition was associated with decreased NF- $\kappa \mathrm{B}$ activity [89]. The relationship between adiponectin and $\mathrm{NF}-\kappa \mathrm{B}$ is under intense investigation right now.

\section{CONCLUSION}

An indirect action of adiponectin is to improve insulin resistance, but it is difficult to clarify the effect of adiponectin in obese patients because of the low levels of circulating adiponectin in obese people. Especially in visceral type obesity, which is always associated with hyperinsulinemia, high levels of TNF $\alpha$, dyslipidemia, and high levels of plasma leptin. These humoral factors interact with each other during cancer development in obese individuals, so the situation is very complicated. Therefore further studies to elucidate the role of these obesity-related humoral factors in cancer should be undertaken. We believe that the best way to clarify the effect of adiponectin in obese individuals is theoretically to administer external adiponectin to them. One of the direct actions of adiponectin in cancer development is the stimulation of the AMPK/mTOR pathway, but other adiponectin-mediated signaling pathways such as the $\operatorname{PPAR} \alpha$ and p38 MAPK pathways should also be investi- gated in various types of cancer. We think that it is a very important point that adiponectin can inhibit colon carcinogenesis and mTOR signaling pathway via activating AMPK only under the high-fat diet condition, not under the normal diet condition in animal study. Therefore we speculate the AMPK/mTOR signaling pathways may play an important role in obesity-related cancer. Identification of the adiponectin target molecules may in the future lead to designs of novel drugs against obesity-related cancers.

\section{ACKNOWLEDGEMENTS}

This work was supported in part by a Grant-in-Aid for research on the Third Term Comprehensive Control Research for Cancer from the Ministry on Health, Labor and Welfare, Japan, to A.N., a grant from the National Institute of Biomedical Innovation (NBIO) to A.N., a grant from the Ministry of Education, Culture, Sports, Science and Technology, Japan (KIBAN-B), to A.N., and a research grant of the Princess Takamatsu Cancer Research Fund.

\begin{tabular}{|c|c|c|}
\hline \multicolumn{3}{|c|}{ ABBREVIATIONS } \\
\hline \multicolumn{3}{|c|}{$\mathrm{ACF}=$ Aberrant crypt foci } \\
\hline \multicolumn{3}{|c|}{ AMPK $=5^{\prime}$-AMP activated protein kinase } \\
\hline \multicolumn{3}{|l|}{ AOM } \\
\hline \multicolumn{3}{|l|}{ fAd } \\
\hline \multicolumn{3}{|r|}{ Globular adiponectin } \\
\hline IGF-1 & $=$ & Insulin like growth factor-1 \\
\hline mTOR & $=$ & Mammalian target of rapamycin \\
\hline S6K & $=$ & p70 ribosomal S6 kinase \\
\hline
\end{tabular}

\section{REFERENCES}

[1] Kadowaki T, Yamauchi T, Kubota N, et al. Adiponectin and adiponectin receptors in insulin resistance, diabetes, and the metabolic syndrome. J Clin Invest 2006; 116: 1784-92.

[2] Kadowaki T, Yamauchi T. Adiponectin and Adiponectin receptors. Endocrine Rev 2005; 26: 439-51.

[3] Barb D, Williams CJ, Neuwirth AK, Mantzoros CS. Adiponectin in relation to malignancies: a review of existing basic research and clinical evidence. Am J Clin Nutr 2007; 86: s858-66.

[4] Nakayama S, Miyoshi Y, Ishihara H, Noguchi S. Growthinhibitory effect of adiponectin via adiponectin receptor 1 on human breast cancer cells through inhibition of S-phase entry without inducing apoptosis. Breast Cancer Res Treat 2008; 112: 405-10.

[5] Cong L, Gasser J, Zhao J, et al. Human adiponectin inhibits cell growth and induces apoptosis in human endometrial carcinoma cells, HEC-1-A and RL95-2. Endocrine-Related Cancer 2007; 14: 713-20.

[6] Sugiyama M, Takahashi H, Hosono K, et al. Adiponectin inhibits colorectal cancer cell growth through the AMPK/mTOR pathway. Int J Oncol 2009; 34: 339-44.

[7] Hotta K, Funahashi T, Arita Y, et al. Plasma concentrations of a novel, adipose-specific protein, adiponectin, in type 2 diabetic patients. Arterioscler Thromb Vasc Biol 2000; 20: 1595-9.

[8] Yamamoto Y, Hirose H, Saito I, et al. Correlation of the adipocytederived protein adiponectin with insulin resistance index and serum high-density lipoprotein-cholesterol, independent of body mass index, in the Japanese population. Clin Sci (London) 2002; 103: 137-42.

[9] Jones J, Clemmons D. Insulin-like growth factors and their binding proteins: biological actions. Endocr Rev 1995; 16: 3-34. 
[10] Smith WJ, Underwood LE, Clemmons DR. Effects of caloric or protein restriction on insulin-like growth factor-1 (IGF-1) and IGFbinding proteins in children and adults. J Clin Endocrinol Metab 1995; 80: 443-9.

[11] Giovannucci E, Michaud D. The role of obesity and related metabolic disturbances in cancers of the colon, prostate, and pancreas. Gastroenterology 2007; 132: 2208-25.

[12] Giovannucci E. Insulin, insulin-like growth factors and colon cancer: a review of the evidence. J Nutr 2001; 131: 3109S-20S.

[13] McKeown-Eyssen G. Epidemiology of colorectal cancer revisited: are serum triglycerides and /or plasma glucose associated with risk? Cancer Epidemiol Biomarkers Prev 1994; 3: 687-95.

[14] Giovannucci E. Insulin and colon cancer. Cancer Causes Control 1995; 6: 164-79.

[15] Bruce WR, Wolever TM, Giacca A. Mechanisms linking diet and colorectal cancer: the possible role of insulin resistance. Nutr Cancer 2000; 37: 19-26.

[16] Bruce WR, Giacca A, Medline A. Possible mechanisms relating diet and risk of colon cancer. Cancer Epidemiol Biomarkers Prev 2000; 9: 1271-9.

[17] Kim YI. Diet, lifestyle, and colorectal cancer: is hyperinsulinemia the missing link? Nutr Rev 1998; 56: 275-9.

[18] Watkins LF, Lewis LR, Levine AE. Characterization of the synergistic effect of insulin and transferring and the cell line. Int J Cancer 1990; 45: 372-5.

[19] Bjork J, Nilsson J, Hultcrantz R, Johansson C. Growth-regulatory effects of sensory neuropeptides, epidermal growth factor, insulin, and somatostatin on the nontransformed intestinal epithelial cell line IEC-6 and the colon cancer cell line HT 29. Scand J Gastroenterol 1993; 28: 879-84.

[20] Aaronson SA. Growth factors and cancer. Science 1991; 254: 1146-53.

[21] MacDonald RS, Thornton WH Jr, Bean TL. Insulin and IGF-1 receptors in a human intestinal adenocarcinoma cell line (CACO2): regulation of $\mathrm{Na}^{+}$glucose transport across the brush border. J Recept Res 1993; 13: 1093-113.

[22] Guo YS, Narayan S, Yallampalli C, Singh P. Characterization of insulinlike growth factor I receptors in human colon cancer. Gastroenterology 1992; 102: 1101-8.

[23] Cohen P, Peehl DM, Rosenfeld RG. The IGF axis in the prostate. Horm Metab Res 1994; 26:81-4.

[24] Shi R, Berkel HJ, Yu H. Insulin-like growth factor-1 and prostate cancer: a meta-analysis. Br J Cancer 2001; 85: 991-6.

[25] Ohmura E, Okada M, Onoda N, Kamiya Y, Murakami H, Tsushima T, Shizume K. Insulin-like growth factor I and transforming growth factor alpha as autocrine growth factors in human pancreatic cancer cell growth. Cancer Res 1990; 50: 103-7.

[26] Stoeltzing O, Liu W, Reinmuth N, et al. Regulation of hypoxiainducible factor- $1 \alpha$, vascular endothelial growth factor, and angiogenesis by an insulin-like growth factor-I receptor autocrine loop in human pancreatic cancer. Am J Pathol 2003; 163: 1001-11.

[27] Renehan $A G$, Zwahlen $M$, Minder $C$, et al. Insulin-like growth factor (IGF)-I, IGF binding protein-3, and cancer risk: systematic review and meta-regression analysis. Lancet 2004; 363: 1346-53.

[28] Schernhammer ES, Holly JM, Pollak MN, Hankinson SE. Circulating levels of insulin-like growth factors, their binding proteins, and breast cancer risk. Cancer Epidemiol Biomarkers Prev 2005; 14: 699-704.

[29] Fletcher O, Gibson L, Johnson N, et al. Polymorphisms and circulating levels in the insulin-like growth factor system and risk of breast cancer: a systematic review. Cancer Epidemiol Biomarkers Prev 2005; 14: 2-19.

[30] Shi R, Yu H, McLarty J, Glass J. IGF-I and breast cancer: a metaanalysis. Int J Cancer 2004; 111: 418-23.

[31] Testa JR, Bellacosa A. AKT plays a central role in tumorigenesis. Proc Natl Acad Sci USA 2001; 98: 10983-5.

[32] Chan TO, Rittenhouse SE, Tsichlis PN. AKT/PKB and other D3 phosphoinositide-regulated kinases: kinase activation by phosphoinositide-dependent phosphorylation. Annu Rev Biochem 1999; 68: 965-1014.

[33] Vivanco I, Sawyers CL. The phosphatidylinositol 3-Kinase AKT pathway in human cancer. Nat Rev Cancer 2002; 2: 489-501.

[34] Endo H, Fujisawa T, Takahashi H, Inamori M, Nakajima A. Author response. Gut 2009; 58: 1169-70.

[35] Miyoshi Y. Association of serum adiponectin levels with breast cancer risk. Clin Cancer Res 2003; 9: 5699-704.
[36] Mantzoros C, Petridou E, Dessypris N, et al. Adiponectin and breast cancer risk. J Clin Endocrinol Metab 2004; 89: 1102-7.

[37] Tworoger SS, Eliassen AH, Kelesidis T, et al. Plasma adiponectin concentrations and risk of incident breast cancer. J Clin Endocrinol Metab 2007; 92: 1510-6.

[38] Cust AE, Stocks T, Lukanova A, et al. The influence of overweight and insulin resistance on breast cancer risk and tumour stage at diagnosis: a prospective study. Breast Cancer Res Treat 2009; 113: 567-76.

[39] Petridou E, Mantzoros C, Dessypris N, et al. Plasma adiponectin concentrations in relation to endometrial cancer: a case-control study in Greece. J Clin Endocrinol Metab 2003; 88: 993-7.

[40] Dal Maso L, Augustin LS, Karalis A, et al. Circulating adiponectin and endometrial cancer risk. J Clin Endocrinol Metab 2004; 89: 1160-3.

[41] Cust AE, Kaaks R, Friedenreich C, et al. Plasma adiponectin levels and endometrial cancer risk in pre- and postmenopausal women. J Clin Endocrinol Metab 2007; 92: 255-63.

[42] Goktas S, Yilmaz MI, Caglar K, et al. Prostate cancer and adiponectin. Urology 2005; 65: 1168-72.

[43] Baillargeon J, Platz EA, Rose DP, et al. Obesity, adipokines, and prostate cancer in a prospective population-based study. Cancer Epidemiol Biomarkers Prev 2006; 15: 1331-5.

[44] Sher DJ, Oh WK, Jacobus S, et al. Relationship between serum adiponectin and prostate cancer grade. Prostate 2008; 68: 1592-8.

[45] Kumor A, Daniel P, Pietruczuk M, Małecka-Panas E. Serum leptin, adiponectin, and resistin concentration in colorectal adenoma and carcinoma (CC) patients. Int J Colorectal Dis 2009; 24: 275-81.

[46] Wei EK, Giovannucci E, Fuchs CS, Willett WC, Mantzoros CS. Low plasma adiponectin levels and risk of colorectal cancer in men: a prospective study. J Natl Cancer Inst 2005; 97: 1688-94.

[47] Lukanova A, Söderberg S, Kaaks R, Jellum E, Stattin P. Serum adiponectin is not associated with risk of CRC. Cancer Epidemiol Biomarkers Prev 2006; 15: 401-2.

[48] Stocks T, Lukanova A, Johansson M, et al. Components of the metabolic syndrome and colorectal cancer risk; a prospective study. Int J Obes (Lond) 2008; 32: 304-14 .

[49] Takahashi H, Takayama T, Yoneda K, et al. Association of visceral fat accumulation and plasma adiponectin with rectal dysplastic aberrant crypt foci in a clinical population. Cancer Sci 2009; 100: 29-32.

[50] Körner A, Pazaitou-Panayiotou K, Kelesidis T, et al. Total and high-molecular-weight adiponectin in breast cancer: in vitro and in vivo studies. J Clin Endocrinol Metab 2007; 92: 1041-8.

[51] Takahata C, Miyoshi Y, Irahara N, et al. Demonstration of adiponectin Receptor 1 and 2 mRNA expression in human breast cancer cell. Cancer Lett 2007; 250: 229-36.

[52] Michalakis K, Williams CJ, Mitsiades N, et al. Serum adiponectin concentrations and tissue expression of adiponectin receptors are reduced in patients with prostate cancer: a case control study. Cancer Epidemiol Biomarkers Prev 2007; 16: 308-13.

[53] Yoneda K, Tomimoto A, Endo H, et al. Expression of adiponectin receptors, AdipoR1 and AdipoR2, in normal colon epithelium and colon cancer tissue. Oncol Rep 2008; 20: 479-83.

[54] Williams CJ, Mitsiades N, Sozopoulos E, et al. Adiponectin receptor expression is elevated in colorectal carcinomas but not in gastrointestinal stromal tumors. Endocr Relat Cancer 2008; 15: 289-99.

[55] Kaklamani VG, Kaklamani VG, Sadim M, Hsi A, et al. Variants of the adiponectin and adiponectin receptor 1 genes and breast cancer risk. Cancer Res 2008; 68: 3178-84.

[56] Kaklamani VG, Wisinski KB, Sadim M, et al. Variants of the adiponectin (ADIPOQ) and adiponectin receptor 1 (ADIPOR1) genes and colorectal cancer risk. JAMA 2008; 300:1523-31.

[57] Hardie DG. AMPK: a key regulator of energy balance in the single cell and the whole organism. Int J Obes (Lond) 2008; 32(Suppl 4): S7-12.

[58] Carling D, Sanders MJ, Woods A. The regulation of AMPactivated protein kinase by upstream kinases. Int J Obes (Lond) 2008; 32(Suppl 4): S55-9. Review.

[59] Lage R, Diéguez C, Vidal-Puig A, López M. AMPK: a metabolic gauge regulating whole-body energy homeostasis. Trends Mol Med 2008; 14: 539-49.

[60] Hezel AF, Bardeesy N. LKB1; linking cell structure and tumor suppression. Oncogene 2008; 27: 6908-19. Review. 
[61] Towler MC, Hardie DG. AMP-activated protein kinase in metabolic control and insulin signaling. Circ Res 2007; 100: 32841. Review.

[62] Fingar DC, Blenis J. Target of rapamycin (TOR): an integrator of nutrient and growth factor signals and coordinator of cell growth and cell cycle progression. Oncogene 2004; 23: 3151-71.

[63] Gingras AC, Raught B, Sonenberg N. Regulation of translation initiation by FRAP/mTOR. Genes Dev 2001; 15: 807-26.

[64] Schmelzle T, Hall MN. TOR, a central controller of cell growth. Cell 2000; 103: 253-62.

[65] Rowinsky EK. Targeting the molecular target of rapamycin (mTOR). Curr Opin Oncol 2004; 16: 564-75.

[66] Jefferies HB, Fumagalli S, Dennis PB, et al. Rapamycin suppresses 5'TOP mRNA translation through inhibition of p70s6k. EMBO J 1997; 16: 3693-704.

[67] Gingras AC, Raught B, Sonenberg N. eIF4 initiation factors: effectors of mRNA recruitment to ribosomes and regulators of translation. Annu Rev Biochem 1999; 68: 913-63.

[68] Gao X, Zhang Y, Arrazola P, et al. Tsc tumour suppressor proteins antagonize amino-acid-TOR signalling. Nat Cell Biol 2002; 4: 699704.

[69] Tee AR, Fingar DC, Manning BD, et al. Tuberous sclerosis complex-1 and -2 gene products function together to inhibit mammalian target of rapamycin (mTOR)-mediated downstream signaling. Proc Natl Acad Sci USA 2002; 99: 13571-6.

[70] Inoki K, Zhu T, Guan KL. TSC2 mediates cellular energy response to control cell growth and survival. Cell 2003; 115: 577-90.

[71] Luo Z, Saha AK, Xiang X, et al. AMPK, the metabolic syndrome and cancer. Trends Pharmacol Sci 2005; 26: 69-76.

[72] Chan S, Scheulen ME, Johnston S, et al. Phase II study of temsirolimus (CCI-779), a novel inhibitor of mTOR, in heavily pretreated patients with locally advanced or metastatic breast cancer. J Clin Oncol 2005; 23: 5314-22.

[73] Duran I, Kortmansky J, Singh D, et al. A phase II clinical and pharmacodynamic study of temsirolimus in advanced neuroendocrine carcinomas. Br J Cancer 2006; 95: 1148-54.

[74] Galanis E, Buckner JC, Maurer MJ, et al. Phase II trial of temsirolimus (CCI-779) in recurrent glioblastoma multiforme: a North Central Cancer Treatment Group Study. J Clin Oncol 2005; 23: 5294-304.

[75] Yee KW, Zeng Z, Konopleva M, et al. Phase I/II study of the mammalian target of rapamycin inhibitor everolimus (RAD001) in patients with relapsed or refractory hematologic malignancies. Clin Cancer Res 2006; 12: 5165-73.
[76] Hudes G, Carducci M, Tomczak P, et al. Temsirolimus, interferon alfa, or both for advanced renal-cell carcinoma. N Engl J Med 2007; 356: 2271-81.

[77] Berg AH, Combs TP, Du X, et al. The adipocyte-secreted protein Acrp30 enhances hepatic insulin action. Nat Med 2001; 7: 947-53.

[78] Yamauchi T, Kamon J, Minokoshi Y, et al. Adiponectin stimulates glucose utilization and fatty-acid oxidation by activating AMPactivated protein kinase. Nat Med 2002; 8: 1288-95.

[79] Wu X, Motoshima H, Mahadev K, et al. Involvement of AMPactivated protein kinase in glucose uptake stimulated by the globular domain of adiponectin in primary rat adipocytes. Diabetes 2003; 52:1355-63.

[80] Huypens P, Moens K, Heimberg H, et al. Adiponectin-mediated stimulation of AMP-activated protein kinase (AMPK) in pancreatic beta cells. Life Sci 2005; 77:1273-82.

[81] Chen H, Montagnani M, Funahashi T, et al. Adiponectin stimulates production of nitric oxide in vascular endothelial cells. J Biol Chem 2003; 278:45021-6.

[82] Ouchi N, Kihara S, Arita Y, et al. Adiponectin, an adipocytederived plasma protein, inhibits endothelial NF-kappaB signaling through a cAMP-dependent pathway. Circulation 2000; 102:1296301 .

[83] Caligiuri A, Bertolani C, Guerra CT, et al. Adenosine monophosphate-activated protein kinase modulates the activated phenotype of hepatic stellate cells. Hepatology 2008; 47:668-76.

[84] Wang C, Mao X, Wang L, et al. Adiponectin sensitizes insulin signaling by reducing p70 S6 kinase-mediated serine phosphorylation of IRS-1. J Biol Chem 2007; 282:7991-6.

[85] Barb D, Neuwirth A, Mantzoros CS, et al. Adiponectin signals in prostate cancer cells through Akt to activate the mammalian target of rapamycin pathway. Endocr Relat Cancer 2007; 14:995-1005.

[86] Marino G, Ugalde AP, Salvador-Montoliu N, et al. Premature aging in mice activates a systemic metabolic response involving autophagy induction. Hum Mol Genet 2008; 17:2196-211.

[87] Fujisawa T, Endo H, Tomimoto A, et al. Adiponectin suppresses colorectal carcinogenesis under the high-fat diet condition. Gut 2008; 57:1531-8.

[88] Khamzina L, Veilleux A, Bergeron S, et al. Increased activation of the mammalian target of rapamycin pathway in liver and skeletal muscle of obese rats: possible involvement in obesity-linked insulin resistance. Endocrinology 2005; 146:1473-81.

[89] Fenton JI, Birmingham JM, Hursting SD, Hord NG. Adiponectin blocks multiple signaling cascades associated with leptin-induced cell proliferation in Apc Min/+ colon epithelial cells. Int J Cancer 2008; 122:2437-45. 